\title{
The serum irisin level in non-diabetic patients with chronic kidney disease
}

İhsan Ateș ${ }^{1}$, Nihal Özkayar ${ }^{1}$, Canan Topçuoğlu ${ }^{2}$ Fatih Dede ${ }^{1}$

${ }^{1}$ Ankara Numune Education and Research Hospital, Department of Nephrology, Ankara, Turkey

${ }^{2}$ Ankara Numune Education and Research Hospital, Department of Biochemistry, Ankara, Turkey

\section{Objectives:}

\section{Methods:}

\section{Results:}

Conclusions:

\section{References:}

Irisin is synthesized in many tissues, especially skeletal muscle, and causes energy expenditure by converting white fat into brown fat. Irisin is a fibronectin type III domain-containing protein 5 that is secreted by human and rat skeletal muscle. Metabolism in patients with chronic kidney disease is essentially a catabolic process that results in a high level of energy expenditure. In chronic kidney disease it is known that as the severity of disease increases catabolic process also increase. The present study aimed to determine if there is a relationship between chronic kidney disease stages and the irisin level.

The study included 90 patients with chronic kidney disease (stages 2-4) (45 male and 45 female) and 32 healthy (18 male and 14 female) controls. Exclusion criteria included diabetes mellitus, acutechronic infection, malignancy, connective tissue disease, thyroid disease, and use of immunosuppressive drugs or steroids. Routine laboratory tests and measurement of the serum irisin level in all participants were performed. The serum irisin level was measured using the ELISA method.

The serum irisin level was significantly lower in the patients with chronic kidney disease than in the control group $(P<0.05)$. The mean serum irisin level in the patient group decreased as the severity of chronic kidney disease increased (stage 2: $22.1 \pm 6.3 \mathrm{ng} / \mathrm{mL}^{-}$; stage 3: $17.5 \pm 3.4 \mathrm{ng} / \mathrm{mL}$; stage 4: $12.9 \pm 3.2 \mathrm{ng} / \mathrm{mL} ; \mathrm{P}<0.001)$. There was a negative correlation between the irisin level, and age $(r=-$ $0.317, P=0.024)$, creatinine $(r=-0.561, P<0.001)$, fasting blood glucose $(r=-0.233, P=0.010)$, and urea $(r=-0.427, P<0.001)$. There was a positive correlation between the serum irisin level and the glomerular filtration rate $(r=0.625, P<0.001)$.

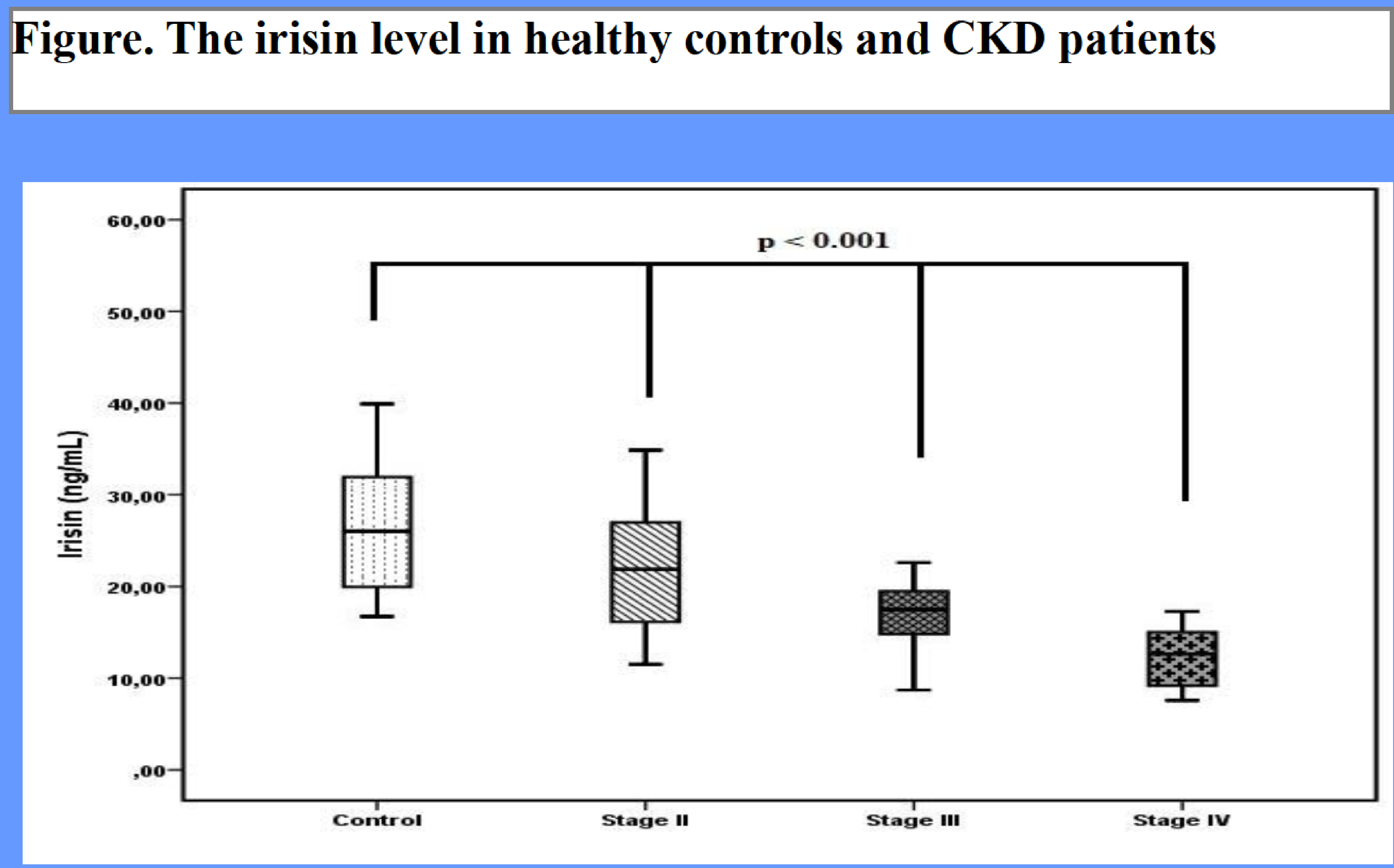

In the chronic kidney disease patients the serum irisin level decreased as the severity of disease increased. Accordingly, the catabolic process, which occurs more frequently in the advanced stages of chronic kidney disease, might also play a role in decreasing the serum irisin level.

1. Levey AS, Stevens LA, Schmid CH, Zhang YL, Castro AF, 3rd, Feldman HI, Kusek JW, Eggers P, Van Lente F, Greene T, Coresh J, Ckd EPI. 2009. A new equation to estimate glomerular filtration rate. Annals of internal medicine 150(9):604-612.

2. Kovesdy CP, Kopple JD, Kalantar-Zadeh K. 2013. Management of protein-energy wasting in non-dialysis-dependent chronic kidney disease: reconciling low protein intake with nutritional therapy. The American journal of clinical nutrition 97(6):1163-1177.

3. Avesani CM, Kamimura MA, Cuppari L. 2011. Energy expenditure in chronic kidney disease patients. Journal of renal nutrition : the official journal of the Council on Renal Nutrition of the National Kidney Foundation 21(1):27-30. 